Gibbons, F. X. \& Gerard, M. (1989) Effects of upward and downward social comparison on mood states. Journal of Social and Clinical Psychology, I, 14-31.

Haghighat, R. (2001) A unitary theory of stigmatisation. Pursuit of self-interest and routes to destigmatisation. British Journal of Psychiatry, I78, 207-215.

Hughes, P. (2000) Stigmatisation as a survival strategy: intrapsychic mechanisms. In Every Family in the Land (ed. A. H. Crisp). www.stigma.org.

Nunnally, J. (1961) Popular Conceptions of Mental Health: Their Development and Change. New York: Holt, Rinehart \& Winston.

R. Haghighat Adult Department, Tavistock Clinic, I20 Belsize Lane, London NW3 5BA

Author's reply: Dr Haghighat's response to my invited editorial comments (Crisp, 2001) upon his paper (Haghighat, 2001) adds to his overall discourse and may illuminate this matter for readers of these articles. I respect his proposition that selfinterest is a basis of the stigmatisation process and all that flows from it. It advances thinking on the matter. Selfinterest could be proposed as an explanatory hypothesis for much of human nature. Within the arena of stigmatisation of people with mental illness probably it can range across human experiential and ingrained biological needs, from its protective value for preservation of self-esteem through to selective mating subserving evolutionary purposes. He has emphasised cultural, political and socio-economic factors. I have suggested that greater emphasis is needed on our existential concerns and fears and the biological substrates to our personal survival strategies in the face of such perceived threats. All require our attention if we are to maximise our capacity to change.

$\mathrm{He}$ appears to despair of us changing our biologically driven nature and behaviours which, in this context, translate into crude defensive categorisations and labelling of those with mental illness, often leading to distancing rather than exploitation. I believe that the best chance of achieving such change is first to acknowledge the power of human biology. In civilised society we have usually striven then to shape and curb it by influencing attitudes and behaviour via moral, educative and legislative channels. We have sometimes succeeded. Importantly, we also need to address individual vulnerabilities and related triggers to such innate mechanisms. I reiterate that they probably importantly include the degrees of personal psychological fragility and related defensiveness, along with their social extensions and projections such as Haghighat emphasises. It may also benefit from clarification of the social handicaps and sometimes the advantages that can accompany some mental illness diatheses.

The College's anti-stigma campaign is about to go public after 3 years of development and planning. Thoughtful input within contributions such as Haghighat's paper, along with this welcome support from the Journal, are at its heart.

Crisp. A. (200I) The tendency to stigmatise. British Journal of Psychiatry, 178, 197-199.

Haghighat, R. (200I) A unitary theory of stigmatisation. Pursuit of self-interest and routes to destigmatisation. British Journal of Psychiatry, 178, 207-215.

A. H. Crisp Psychiatric Research Unit, Atkinson Morley's Hospital, 3I Copse Hill, Wimbledon, London SW20 ONE

\section{Stigma caused by psychiatrists}

Chaplin (2000) could have made an interesting read but unfortunately seemed to miss making any particular point. The effects of medication and Mental Health Act assessments can and do have powerful effects on both the ill person and his or her family. Alas, Chaplin failed to expand on a major issue - the attitudes some psychiatrists hold have far more devastating effects on their patients than either medication or the Mental Health Act.

I have written elsewhere (Corker, 2001) about the deeply harming effects that stigmatisation and discrimination by psychiatrists can have on people who may have suffered mental illness and may or may not have been their patients. While many articles have been written about the stigma of mental illness, too little has been said about the effect that the attitude of mental health professionals may have on patients.

For the patient the mental health professional must maintain a position of trust and also remember that they provide the building blocks for modelling at a point of extreme vulnerability in the life of the patient. As a mental health professional for 20 years, both in the National Health Service and private practice, I have also experienced the discrimination and stigma of being a patient during and following two major depressive illnesses. The experience of being ill has certainly changed my life and resulted in major losses; worse is the way in which the illnesses have been used by fellow professionals, both medical and non-medical, to stigmatise and discriminate. I do admit to making mistakes as a result of illness but would have expected that this would be seen as the result of illness, where poor decision-making is acknowledged as one of the key signs.

I agree with Chaplin that psychiatrists "must be prepared to identify and challenge our own prejudices and attempt to modify our clinical practice". First and foremost, this requires a sense of humility to examine a personal approach. Second, attitudes and practices that need to be changed must be identified. Third, the responsibility needed to make the change must be accepted.

Chaplin, R. (2000) Psychiatrists can cause stigma too (letter). British Journal of Psychiatry, I77, 467.

Corker, E. (200I) Stigma and discrimination - the silent disease. International Journal of Clinical Practice, $\mathbf{5 5}$ in press.

E. Corker Address supplied. Correspondence $c / 0$ The British journal of Psychiatry, 17 Belgrave Square, London SWIX 8PG

\section{Cognitive therapy in schizophrenia}

In the course of a favourable review of cognitive therapy in schizophrenia, Thornicroft \& Susser (2001) cite the recent trial by Sensky et al (2000), but fail to mention that it had negative results. This 90-patient, 9-month randomised controlled trial, carried out under blind conditions, compared this form of treatment with a control intervention (befriending) and found no significant difference between the two. It is true that differences emerged 9 months after completion of treatment, but this latter part of the study was uncontrolled.

Of the other trials of cognitive therapy cited in their article, that of Drury et al (1996) did not use blind evaluations, and that of Kuipers et al (1997) employed neither blind evaluations nor a condition to control for the non-specific effects of intervention (the Hawthorne effect). Only one other published study (Tarrier et al, 1998) incorporated both these design features; this found a non-significant advantage of cognitive therapy over supportive counselling (Curtis, 1999). 